\title{
Decompensated cor pulmonaleas the first manifestation of adult-onset myopathy
}

\author{
Kurz, D ; Aguzzi, A ; Scherer, T A
}

\begin{abstract}
A 46-year-old white female was admitted for decompensated cor pulmonale (CP). It had not interfered with her daily activities and she had not experienced shortness of breath, fatigue or muscle weakness prior to the onset of right heart failure. A thorough investigation revealed severe generalized muscle weakness with restrictive chest bellows disease and secondary CP (mean pressure in the pulmonary artery $60 \mathrm{~mm} \mathrm{Hg}$ ). After having refused respiratory support the patient died a few days after admission. The muscle biopsy was consistent with adult-onset acid-maltase deficiency. This is a rare case of metabolic myopathy presenting as decompensated $\mathrm{CP}$ without previous symptoms of muscle weakness. This condition can easily be treated with nocturnal ventilatory support, improving the quality and length of life.
\end{abstract}

DOI: https://doi.org/10.1159/000029285

Posted at the Zurich Open Repository and Archive, University of Zurich

ZORA URL: https://doi.org/10.5167/uzh-1824

Journal Article

Published Version

Originally published at:

Kurz, D; Aguzzi, A; Scherer, T A (1998). Decompensated cor pulmonaleas the first manifestation of adult-onset myopathy. Respiration, 65(4):317-319.

DOI: https://doi.org/10.1159/000029285 
David Kurz a

Adriano Aguzzi ${ }^{\mathrm{b}}$

Thomas A. Scherer ${ }^{\text {a }}$

a Department of Internal Medicine and Division of Pulmonary Diseases,

Triemli City Hospital and

b Department of Pathology, Institute of Neuropathology, University Hospital, Zurich, Switzerland

\section{Decompensated Cor pulmonale as the First Manifestation of Adult-Onset Myopathy}

\section{Key Words}

Pulmonary heart disease, etiology

Respiratory insufficiency, etiology Glucan 1,4- $\alpha$-glucosidase, deficiency Muscular diseases, adult

Muscular diseases, pathology

\begin{abstract}
A 46-year-old white female was admitted for decompensated cor pulmonale (CP). It had not interfered with her daily activities and she had not experienced shortness of breath, fatigue or muscle weakness prior to the onset of right heart failure. A thorough investigation revealed severe generalized muscle weakness with restrictive chest bellows disease and secondary CP (mean pressure in the pulmonary artery $60 \mathrm{~mm} \mathrm{Hg}$ ). After having refused respiratory support the patient died a few days after admission. The muscle biopsy was consistent with adult-onset acid-maltase deficiency. This is a rare case of metabolic myopathy presenting as decompensated $\mathrm{CP}$ without previous symptoms of muscle weakness. This condition can easily be treated with nocturnal ventilatory support, improving the quality and length of life.
\end{abstract}

\section{Introduction}

Chronic neuromuscular diseases are frequently complicated by pulmonary problems. Recurrent pneumonia due to hypoventilation or aspiration, atelectasis, pulmonary embolism, and cor pulmonale (CP) are major causes of morbidity among these patients, and respiratory failure is a leading cause of death. However, when respiratory failure is the presenting symptom of a neuromuscular disorder, diagnosis may be difficult. We present a case of adult-onset metabolic myopathy presenting with decompensated $\mathrm{CP}$ as the first and only manifestation.

\section{Case Report}

The 46-year-old white female was admitted for investigation and treatment of decompensated CP. Three months previously she had developed bilateral ankle edema and mild shortness of breath. The workup by a cardiologist revealed severe pulmonary hypertension with CP. Systolic pressure in the pulmonary artery as estimated by Doppler echocardiography was $60 \mathrm{~mm} \mathrm{Hg}$. No intracardiac shunts or pathology of the left heart were observed. She was referred to a pulmonary specialist for further investigation.

Ten days later her condition deteriorated rapidly due to an upper respiratory tract infection requiring emergency admission to our hospital.

Prior to the onset of right heart failure she and her relatives had not observed any signs of muscle weakness or gradual deterioration in her condition. She worked as a secretary in a busy medical office and perceived no interference with her daily activities, had never been seriously ill or been admitted to a hospital. She was single, had never been pregnant and did not take any medication. Alcohol was consumed only occasionally and tobacco or recreational drugs were never used. Apart from being underweight since childhood, her psychomotor development had been normal. Her family history was unremarkable.

On physical examination the woman was alert, cyanotic, dyspneic at rest, had bilateral ankle edema and marked jugular venous distension. The respiratory rate was 26 , the blood pressure $130 / 90 \mathrm{~mm}$ $\mathrm{Hg}$ and the heart rate 96 . Generalized muscle atrophy, accentuated in

\begin{tabular}{ll}
\hline KARGER & ( 1998 S. Karger AG, Basel \\
Fax +4161306 12 34 & 0025-7931/98/0654-0317\$15.00/0 \\
$\begin{array}{l}\text { E-Mail karger@karger.ch } \\
\text { www.karger.com }\end{array}$ & Accessible online at: \\
http://BioMedNet.com/karger
\end{tabular}

\footnotetext{
Thomas A. Scherer, MD

Pulmonary Division, Triemli City Hospital

Birmensdorferstrasse 497

CH-8063 Zürich (Switzerland)

Tel. +41 146611 11, ext. 81619, Fax +41 146626 02, E-Mail Thsche@swissonline.ch
} 


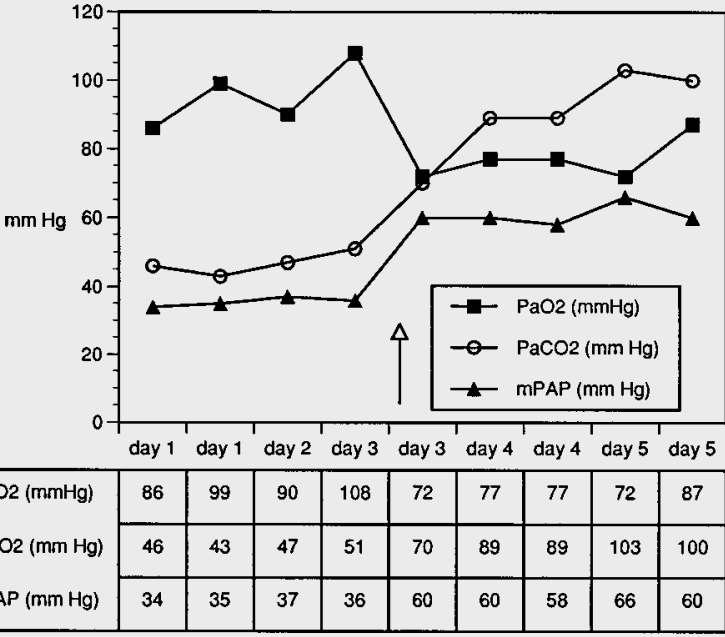

Fig. 1. Arterial blood gases and mean pulmonary artery pressures on full mechanical ventilatory support and during spontaneous breathing. It demonstrates almost full reversibility of the pulmonary hypertension on mechanical ventilation. The arrow indicates time of extubation. $\mathrm{mPAP}=$ Mean pulmonary artery pressure; $\mathrm{PaO}_{2}=$ arterial oxygen tension; $\mathrm{PaCO}_{2}=$ arterial carbon dioxide tension.

the regions of the trunk and neck, was observed. Tendon reflexes were ++ and sensation was entirely intact.

Laboratory results including creatinine kinase were normal except for elevated liver enzymes (aspartate aminotransferase $580 \mathrm{U} / \mathrm{l}$, alanine aminotransferase 1,331 U/l). Screening tests for hepatitis and human immunodeficiency virus were negative. An arterial blood gas analysis while breathing room air showed a $\mathrm{pO}_{2}$ of $4.3 \mathrm{kPa}(32.25$ $\mathrm{mm} \mathrm{Hg})$, a $\mathrm{pCO}_{2}$ of $9.53 \mathrm{kPa}(71.5 \mathrm{~mm} \mathrm{Hg})$, and a $\mathrm{pH}$ of 7.34. On 4 liters of oxygen via nasal cannula the $\mathrm{pO}_{2}$ was $15.9 \mathrm{kPa}(119 \mathrm{~mm}$ $\mathrm{Hg})$, the $\mathrm{pCO}_{2} 16.2 \mathrm{kPa}(121.5 \mathrm{~mm} \mathrm{Hg})$ and the $\mathrm{pH} 7.12$.

An electrocardiogram showed a normal sinus rhythm with p-pulmonale and right axis deviation of $135^{\circ}$. An X-ray of the chest disclosed prominent pulmonary arteries with bilateral pleural effusions. An echocardiogram confirmed the findings of the prior exam. The right heart was dilated and hypertrophied with marked tricuspid regurgitation.

While undergoing fiberoptic bronchoscopy to remove secretions the patient experienced respiratory arrest, necessitating intubation and mechanical ventilation. A balloon-tipped flow directed pulmonary artery catheter was inserted, showing a mean pulmonary artery pressure of $35 \mathrm{~mm} \mathrm{Hg}$ during mechanical ventilation. However, when breathing spontaneously, it increased to $62 \mathrm{~mm} \mathrm{Hg}$ even though the patient maintained good arterial oxygen saturation (fig. 1).

By that time a neuromuscular disease as the cause of the $\mathrm{CP}$ was suspected and confirmed by electromyographic testing. Other causes of $\mathrm{CP}$ such as pulmonary vascular or interstitial lung diseases were excluded.

After extubation, the patient was markedly tachypneic. While breathing spontaneously without any support, her respiratory rate rose continuously to 48 per minute with a corresponding rise in arterial $\mathrm{pCO}_{2}$ to $13.7 \mathrm{kPa}(103 \mathrm{~mm} \mathrm{Hg})$, whilst her arterial oxygen saturation was kept around $92 \%$ with supplemental oxygen. On noninvasive nasal ventilation (each breath triggered by the patient) with 2-5 liters of supplemental oxygen she was able to maintain the $\mathrm{pCO}_{2}$ between 8 and $9 \mathrm{kPa}(65 \mathrm{~mm} \mathrm{Hg})$ with a respiratory rate between 20 and 30 per minute. Fluoroscopy of the diaphragms revealed limited but symmetrical motion. Her maximal inspiratory and expiratory pressures were $-10 \mathrm{~cm} \mathrm{H}_{2} \mathrm{O}$ and $+20 \mathrm{~cm} \mathrm{H}_{2} \mathrm{O}$, respectively, and the peak expiratory flow 100 liters $/ \mathrm{min}$.

Nemaline body myopathy and adult-onset acid-maltase deficiency were considered possible etiologies. The patient consented to a muscle biopsy but refused further ventilatory support. She had a very rapid downhill course and expired before the muscle biopsy could be performed.

Autopsy disclosed a dilated and hypertrophied right heart. No structural changes in the pulmonary vascular bed were found. Apart from the sequelae of right heart failure all internal organs were normal, especially the heart and the liver. There was a marked generalized atrophy of the skeletal muscles, which also involved the respiratory muscles (diaphragm, intercostals, scalenes, and sternocleidomastoids).

Microscopic preparations of the deltoid and the quadriceps muscles revealed prominent myopathic features with fibers of highly irregular caliber and numerous necrotic fibers. Accumulations of periodic acid-Schiff-positive, diastase-sensitive amorphous material were found. Stains for ATP-ase ( $\mathrm{pH}$ 4.2) did not show fiber-type grouping, making neurogenic myopathy unlikely. No myositis was seen. The respiratory muscles were not histologically examined.

These pathologic findings were diagnostic for metabolic myopathy due to pathologic glycogen storage disease, and together with the clinical presentation they were consistent with adult-onset acid-maltase deficiency.

\section{Discussion}

Acid-maltase deficiency is a rare disorder of autosomal recessive inheritance with pathologic glycogen storage due to decreased activity of the lysosomal enzyme $\alpha-1,4$-glucosidase (= acid maltase). In the adult type the skeletal muscles are involved without participation of the myocardium and the liver. These patients typically develop a progressive limb girdle myopathy in the 2 nd or 3 rd decade of life, but presentation up to the age of 65 has been reported. Unlike in other myopathies, the respiratory muscles are frequently involved [1-5]. Selective muscle involvement has been observed, and when only the diaphragm is affected, patients may present with respiratory failure $[2,4,6]$. The presented case of severe metabolic myopathy due to glycogen storage pathology with clinically predominant involvement of the respiratory muscles is consistent with acid-maltase deficiency. However, we are unaware of other reports of acid-maltase deficiency presenting as decompensated cor pulmonale. 
Our patient showed some other unique features. Considering the short interval from the first symptoms of $\mathrm{CP}$ to severe respiratory failure, the course was rapidly progressive. The final decompensation was caused by an upper respiratory tract infection, a typical complication of neuromuscular ventilation disorders. Despite repeated questioning of the patient and her relatives, no clinical symptoms could be detected prior to the onset of right heart failure. This may be due to the very slow deterioration of respiratory muscle function. On the other hand, the lack of any structural changes in the pulmonary vascular bed and the almost complete reversibility of pulmonary hypertension with sufficient ventilation are in keeping with a relatively short duration of respiratory failure. Nevertheless, the excessive hypercapnia tolerated by our patient, reaching peak values of $16.1 \mathrm{kPa}(121 \mathrm{~mm} \mathrm{Hg})$ with an arterial blood $\mathrm{pH}$ of 7.1 , points to an acute or chronic hypoventilation.

Considering the clinical presentation and the insidious onset of symptoms, central alveolar hypoventilation might be included in the differential diagnosis. However, the generalized muscle atrophy with involvement of the respiratory muscles, the documented disorder of the glycogen metabolism in the skeletal muscles and their marked weakness point to a hypoventilation secondary to respiratory muscle disease. The fact that the patient retained more $\mathrm{CO}_{2}$ on unsupported ventilation and was able to lower the $\mathrm{pCO}_{2}$ on noninvasive assisted ventila- tion is consistent with our hypothesis that the muscle weakness and not the central drive was responsible for the hypercarbia.

The development of CP secondary to neuromuscular disease has been described, but almost never occurs without preceding signs of muscle weakness [4, 7]. We assume that severe chronic hypoventilation during sleep and restrictive chest bellows disease caused the CP. Despite adequate oxygenation the pulmonary artery pressures were markedly elevated while breathing spontaneously. This is consistent with pulmonary hypertension secondary to restrictive chest bellows disease. Her sedentary lifestyle probably contributed to the scarcity of early symptoms.

In summary, we describe an unusual case of rapidly decompensating $\mathrm{CP}$ as a sequel of adult-onset metabolic myopathy with involvement of the respiratory muscles. Although rare, this disorder should be included in the differential diagnosis of pulmonary hypertension and CP. In many cases it can be treated easily with long-term home ventilatory support, improving the quality and length of life $[1,2,4,5,7]$.

\section{Acknowledgement}

We thank Professor O. Oelz, head of the Department of Internal Medicine, Triemli City Hospital, Zürich, for carefully reviewing the manuscript and for his valuable comments.

\section{References}

1 Moufarrej NA, Bertorini TE: Respiratory insufficiency in adult-type acid maltase deficiency. South Med J 1993;86:560-567.

2 Rosenow EC III, Engel AG: Acid maltase deficiency in adults presenting as respiratory failure. Am J Med 1978;64:485-491.

3 Engel GA, Gomez MR, Seybold ME, Lambert EH: The spectrum and diagnosis of acid maltase deficiency. Neurology 1973;23:95-106.

4 Howard RS, Wiles CM, Hirsch NP, Spencer GT: Respiratory involvement in primary muscle disorders: Assessment and management. Q J Med 1993;86:175-189.
5 Keunen RWM, Lambregts PCLA, Op de Coul AAW OP, Joosten EMG: Respiratory failure as initial symptom of acid maltase deficiency. $\mathbf{J}$ Neurol Neurosurg Psychiatry 1984;47:549552.

6 Sivak ED, Salanga VD, Wilbourn AJ, Mitsumoto $\mathrm{H}$, Golish J: Adult-onset acid maltase deficiency presenting as diaphragmatic paralysis. Ann Neurol 1981;9:613-615.

7 White J, Bullock RE, Hudgson P, Gibson GJ: Neuromuscular disease, respiratory failure and cor pulmonale. Postgrad Med J 1992;68:820823.

Cor pulmonale due to Myopathy 